Protecting America's Future

\section{Assessment of Pulse Reactor Fuel for Packaging and Accountability}

\author{
Jon D. Long
}

\section{Y-12}

\section{NATIONAL} SECURITY COMPLEX

June 2005

Nuclear Materials Control and Accountability Y-12 National Security Complex Oak Ridge, Tennessee 


\section{SCLAI MER}

This work of authorship and those incorporated herein were prepared by Contractor as accounts of work sponsored by an agency of the United States Government. Neither the United States Government nor any agency thereof, nor Contractor, nor any of their employees, makes any warranty, express or implied, or assumes any legal liability or responsibility for the accuracy, completeness, use made, or usefulness of any information, apparatus, product, or process disclosed, or represents that its use would not infringe privately owned rights. Reference herein to any specific commercial product, process, or service by trade name, trademark, manufacturer, or otherwise, does not necessarily constitute or imply its endorsement, recommendation, or favoring by the United States Government or any agency or Contractor thereof. The views and opinions of authors expressed herein do not necessarily state or reflect those of the United States Government or any agency or Contractor thereof.

\section{COPYRI GHT NOTI CE}

This document has been authored by a subcontractor of the U. S. Government under contract DE-AC0500OR-22800. Accordingly, the U. S. Government retains a paid-up, nonexclusive, irrevocable, worldwide license to publish or reproduce the published form of this contribution, prepare derivative works, distribute copies to the public, and perform publicly and display publicly, or allow others to do so, for U. S.

Government purposes. 


\title{
Assessment of Pulse Reactor Fuel for Packaging and Accountability
}

\author{
Jon Long \\ BWXT Y-12, Y-12 National Security Complex \\ Oak Ridge, Tennessee USA 37831
}

\begin{abstract}
In 2003, the U.S. Army Developmental Test Command (DTC) determined that the operation of a fast pulse nuclear reactor under their command would cease. The decommissioning of the facility would free up resources for the global war on terrorism. A key element of the process to decommission the facility was to relocate the reactor fuel. The reactor fuel was originally supplied by, and owned, by the U.S. Department of Energy. The U.S. Army requested that the DOE make preparations for the retrieval of the fuel by no later than the end of fiscal year 2004.

The schedule requested by the U.S. Army presented a number of technical and regulatory hurdles that had to be overcome. The facility was still operational, completing final experiments prior to facility closure. Continued operation of the reactor provided for an indeterminate fuel assessment with the potential for high radiation dose rates being encountered during package loading and shipment. This paper presents the system approach that was taken to determine the most suitable means to safely and compliantly package and ship the material by the requested schedule. Specifically, it discusses what assessments were performed to determine if an existing packaging could meet potential changes governing packaging and transportation regulations. Evaluation of the package shielding requirements performed to ensure safe handling by the retrieval team members is also discussed. Requirements and methodology utilized to determine material accountability and acceptance at both the shipping and receiving sites are presented. The material was evaluated, packaged, and transported prior to the requested date meeting the goal of the DOD without impact to the safety of team members or the public. Additionally, enhancement of material security was made by its relocation and consolidation as well as allowing for resource reallocation by the U.S. Army.
\end{abstract}

\section{Reactor/Fuel Description}

The Aberdeen Pulse Radiation Facility (APRF) reactor is a bare unreflected and unmoderated cylindrical assembly of a highly enriched uranium alloy consisting of $90 \mathrm{wt}$ percent uranium and $10 \mathrm{wt}$ percent molybdenum (U-10 Mo). The core consists of a cylindrical outer shell of stacked annular fuel plates (commonly called rings) bolted together and a movable inner safety block. The core height is variable depending upon the number of plates assembled for use. Control rods and pulse rods pass through vertical cavities within the stack of fuel plates. All rods, bolts and safety blocks are also U-10 Mo. The U-10 Mo alloy has excellent dimensional stability under thermal cycling. A sample irradiation chamber is located concentric with the vertical axis of the core. The reactor is used for both irradiating samples within the core assembly and for conducting

Institute of Nuclear Materials Management $-46^{\text {th }}$ Annual Meeting July 10-14, 2005 - Phoenix, Arizona USA 


\section{Assessment of Pulse Reactor Fuel for Packaging and Accountability}

radiation effects modeling experiments on item outside the assembly. The supporting structure for the drives and other reactor components is located above the core to allow it to be suspended from a transporter so that the area below and around the core is available for irradiation of experimental material. A cutaway view of a typical core assembly is depicted in Figure 1.

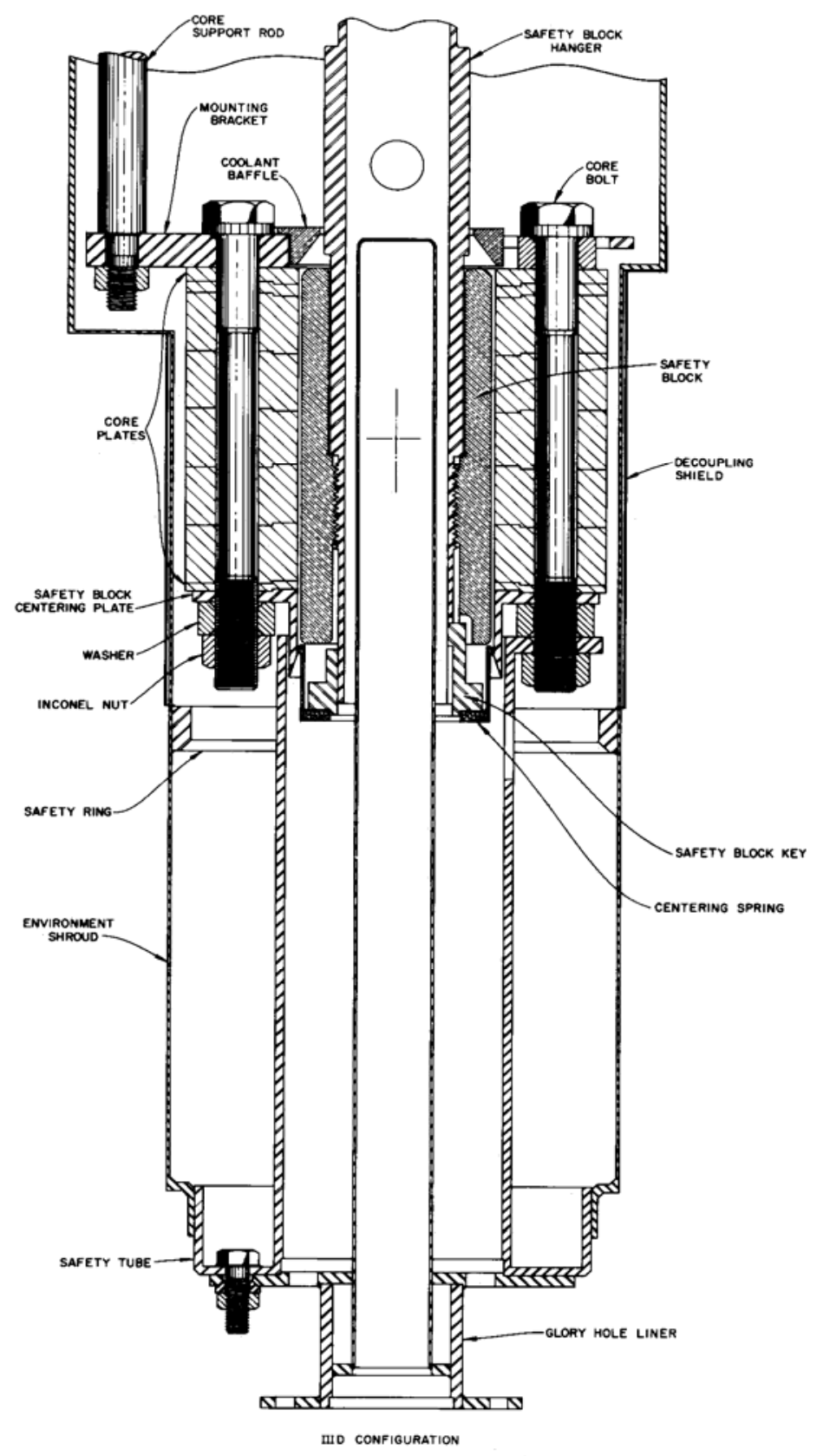

Figure 1. Vertical cutaway of a typical core assembly.

Institute of Nuclear Materials Management $-46^{\text {th }}$ Annual Meeting July 10-14, 2005 - Phoenix, Arizona USA 


\section{Assessment of Pulse Reactor Fuel for Packaging and Accountability}

\section{The Goal}

It was desired to evaluate package options and determine the best suitable means by which to safely package, ship, and store the material in a regulatory compliant manner while meeting the customers schedule at a reasonable cost. The benefit would be the consolidation of nuclear material elsewhere allowing the U.S. Army to reallocate resources, both financial and manpower utilization.

\section{The Challenges}

Initial inquiries by the DOE for the Army requested potential packaging options, schedules and cost estimates. The material content for package evaluation would consist of multiple components: plates, rods, bolts and safety blocks. The safety blocks would be the most massive component. Fuel components from different core assemblies needed to be evaluated for shipment, including "cold" components along with the "hot" components from the core still in operation. The reactor was to continue operations until early 2004. Complicating the determination of an acceptable package for shipment of the material were two major factors. First, continued operations of the one assembly meant that the fission products produced during the fission process would be indeterminate until such a time as the reactor was shut down and the fission product yield could be calculated. The specific fission product inventory along with the quantity of uranium is utilized in the determination of any necessary shielding requirements as well as the containment, thermal and criticality considerations for the package to meet the regulatory requirements specified in 10 CFR 71, Packaging and Transportation of Radioactive Material. The potential for excessive dose rates during packing operations was also a significant concern.

The second major factor which could impact package alternatives was the imminent changes to 10 CFR 71 . The initial material evaluation would be completed and in-depth analyses for package options would begin prior to the publication of the Final Rule. Also unknown was the implementation date for the Final Rule. The risk was that any package analyses could be invalidated by new or revised regulatory requirements.

\section{Package Alternatives}

The schedule presented by the U.S. Army for material to be removed from the Aberdeen Proving Ground by end of FY 2004 presented a significant time constraint. Any scoping evaluations would have to consider the worst case possibility of maximum fission product yield for the core still in operation. The inventory determination would be based upon anticipated reactor operational time for conducting and completing the planned experiments. The calculated inventory for the worst case was supplied by APRF staff members for use by engineers and analysts supporting the BWXT Y-12 National Security Complex (NSC) Packaging Engineering organization. The schedule time constraint also

$$
\text { Institute of Nuclear Materials Management }-46^{\text {th }} \text { Annual Meeting }
$$
July 10-14, 2005 - Phoenix, Arizona USA 


\section{Assessment of Pulse Reactor Fuel for Packaging and Accountability}

meant that only one package could be evaluated and would have to be the single solution for both the "hot" and "cold" fuel plates as well as the "hot" safety block. The DOT $6 \mathrm{M} 2 \mathrm{R}$ specification container would be sufficient for the "cold" rods, bolts and safety blocks.

Commercial sources of packages for spent reactor fuel were quickly eliminated due to their large size and excessive weight. The facility where the material would be packaged was limited in floor space and height. Therefore, the best option for a package was an inhouse design Drum Type (DT) package.

The initial consideration was the utilization of the DT-22 package as it had previously been approved for uranium shipments as well as its relative compact size. The time limitations indicated that even though the DT-22 would be appropriate for the fuel that had not been in use for some time, the potential dose rates for non-exclusive use shipments might preclude the use of the DT-22 due to its small size without the use of internal shielding for the "hot" material. Initial shielding calculations indicated that internal shielding would be required for the DT-22 and that the amount required would elevate the package weight above what had previously been approved by the U.S. DOE Albuquerque Service Center, Packaging Certification Division (DOE AL-SC PCD). Thus, the DT-22 was eliminated from consideration.

The ES-2100 and DPP-2 were also considered. These were eliminated primarily due to content limitations as well as testing and certification time constraints. Another option was a new package designed and certified to impending regulations. The cost of approximately 3.5 million dollars and a scheduled of three years to design, test, certify, and fabricate shipping packaging eliminated this from consideration.

The package which had the second most potential behind the DT-22 was the DT-23. It had previously been evaluated and a Safety Analysis Report for Packaging (SARP) completed for pulse reactor fuel. The somewhat larger size of the DT-23 as compared to the DT-22 was both an advantage and a disadvantage. The benefit was that there would be additional distance from the "hot" content once loaded. The disadvantage of the DT23 was that it presented a cumbersome package to handle and load into transport vehicles for shipment as no loading dock was available at the APRF. An exemption for the DT-23 could also be pursued if it was determined that impending regulatory requirements would prevent its certification for the proposed content prior to the regulatory implementation date. Thus, the DT-23 was the package determined to be the best possible solution meeting cost and schedule requirements as well as the known and anticipated regulatory requirements.

\section{Analyses and Preparation of Safety Analysis Report for Packaging}

The package evaluation began in late 2003 with the efforts concentrated on the structural, thermal, containment, criticality and shielding analyses. In the structural, thermal, and criticality areas, previous design analyses in conjunction with full-scale testing demonstrated the DT-23 shipping package was compliant with the requirements of 10 CFR 71 and 49 CFR 100-178. The current analyses indicated that the pulse reactor fuel content was bounded by previously certified DT-23 shipping packages. Calculational and Finite Element Analyses (FEA) were completed for both Normal Conditions of Transport

$$
\text { Institute of Nuclear Materials Management }-46^{\text {th }} \text { Annual Meeting }
$$
July 10-14, 2005 - Phoenix, Arizona USA 


\section{Assessment of Pulse Reactor Fuel for Packaging and Accountability}

(NCT) and Hypothetical Accident Conditions (HAC). Heat generation by the fuel would be insignificant. Criticality analysis indicated the material could be transported safely in the DT-23.

Containment criteria and shielding analysis was dependent upon the worst case scenario for fission and daughter product inventory. Calculational analyses indicated that the containment criteria established by 10 CFR 71 for both NCT and HAC would be satisfied. Shielding analyses were performed using the MORSE Monte Carlo Transport Code System and the ORIGEN-S computer code with a conservative model. The two most massive components, a safety block and largest plate, were modeled utilizing the estimated fission product inventory data supplied by APRF personnel for the assembly components still in operation. The conservative shielding analysis indicated the potential for a Radiation Transport Index (TI) near the regulatory limit for non-exclusive use shipments.

As the actual dose rates expected during packing operations was currently unknown, a convenience can for the "hot" safety block was designed in conjunction with the package analyses. The design criteria for the can specified that it should be relatively easy to handle, load and provide as much shielding for both personnel handling the can as well as reducing the dose rate on the external surface of the package. Fabrication costs were also to be minimal. It would also need to be suitable for use in the 6M2R for the rods, bolts, and safety blocks as well as the DT-23 for the "hot" safety block. A diagram of the convenience can assembly is shown in figure 2.
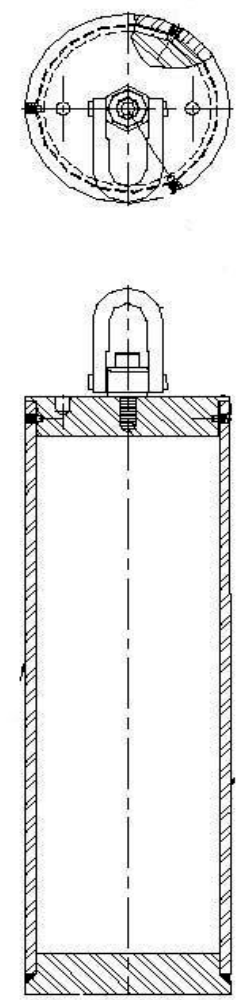

Figure 2. Convenience Can Assembly for Fuel Rods/Bolts/Safety Blocks. Institute of Nuclear Materials Management $-46^{\text {th }}$ Annual Meeting July 10-14, 2005 - Phoenix, Arizona USA 


\section{Assessment of Pulse Reactor Fuel for Packaging and Accountability}

A commercially available film can was determined to be suitable for use with the fuel plates as significant self-shielding would occur.

As the safety analysis for the packaging was nearing completion, reactor operations ceased. The operational time for the reactor was determined to be $70 \%$ of what was initially estimated to complete the planned tests. Therefore, the fission product inventory would be less than the estimated yield used in the calculational models. The TI determined subsequent to packing operations would be less than that predicted by the worst case analysis.

On January 26, 2004, the U.S. Nuclear Regulatory Commission (NRC) published the changes to 10 CFR 71 in the Federal Register (Volume 69, No. 16) with an implementation date of October 1, 2004. The October 1 date coincided with the project completion date requested by the Army. Correspondence had previously been submitted from the National Nuclear Security Administration Y-12 Site Operations (NNSA YSO) to the AL-SC PCD requesting review requirements for a Y-12 SARP submittal and certification requirements pending the NRC publication of the regulatory changes. A SARP submittal date of March 31, 2004 was agreed upon to allow sufficient time for the completion of the SARP by Y-12 Packaging Engineering as well as the subsequent review efforts by the PCD. However, data generated during the analysis would be submitted in portions prior to the complete SARP submittal to allow for independent review as each analysis was completed. All deadlines were met with the SARP also submitted for use by the facility safety personnel to be utilized in completion of facility safety analyses for receipt and storage of the material.

PCD completed their review and submitted comments for resolution. All comments were satisfactorily resolved and the PCD issued an Offsite Transportation Certificate (OTC) in early September.

\section{Fuel Retrieval and Transfer}

As the DOE was the owner of the material and registered user of the DT-23, Y-12 NSC personnel would perform the packing operations at the APRF. The retrieval team was assembled and trained. Plans were made and procedures written and approved. Material handling concerns were given special emphasis from both radiation protection and industrial safety perspectives.

The Material Control and Accountability (MC\&A) plan would be verified by a MC\&A representative during packing operations. Each component serial number etched on the component would be verified against fabrication documentation. The weight of each item would be recorded. Weights would be compared to previous documentation. Additionally, a passive gamma ray measurement would be taken on the "cold" components. Tamper Indicating Devices (TIDs) would be applied to both the convenience cans and the confinement drums of each package.

The packing evolutions of the material were on-going at the APRF with insignificant issues encountered. Transport vehicles were loaded and shipments completed prior to the October 1 deadline.

Institute of Nuclear Materials Management $-46^{\text {th }}$ Annual Meeting July 10-14, 2005 - Phoenix, Arizona USA 


\section{Assessment of Pulse Reactor Fuel for Packaging and Accountability}

\section{Project Assessment}

Successful removal of the material by the deadline was accomplished by the efforts of many organizations and individuals. Figure 3, the System Integration and Synthesis Flowchart, shows the interdependence of the requirements for the successful completion of the project and is also an indicator of how decisions and analyses may affect subsequent steps.

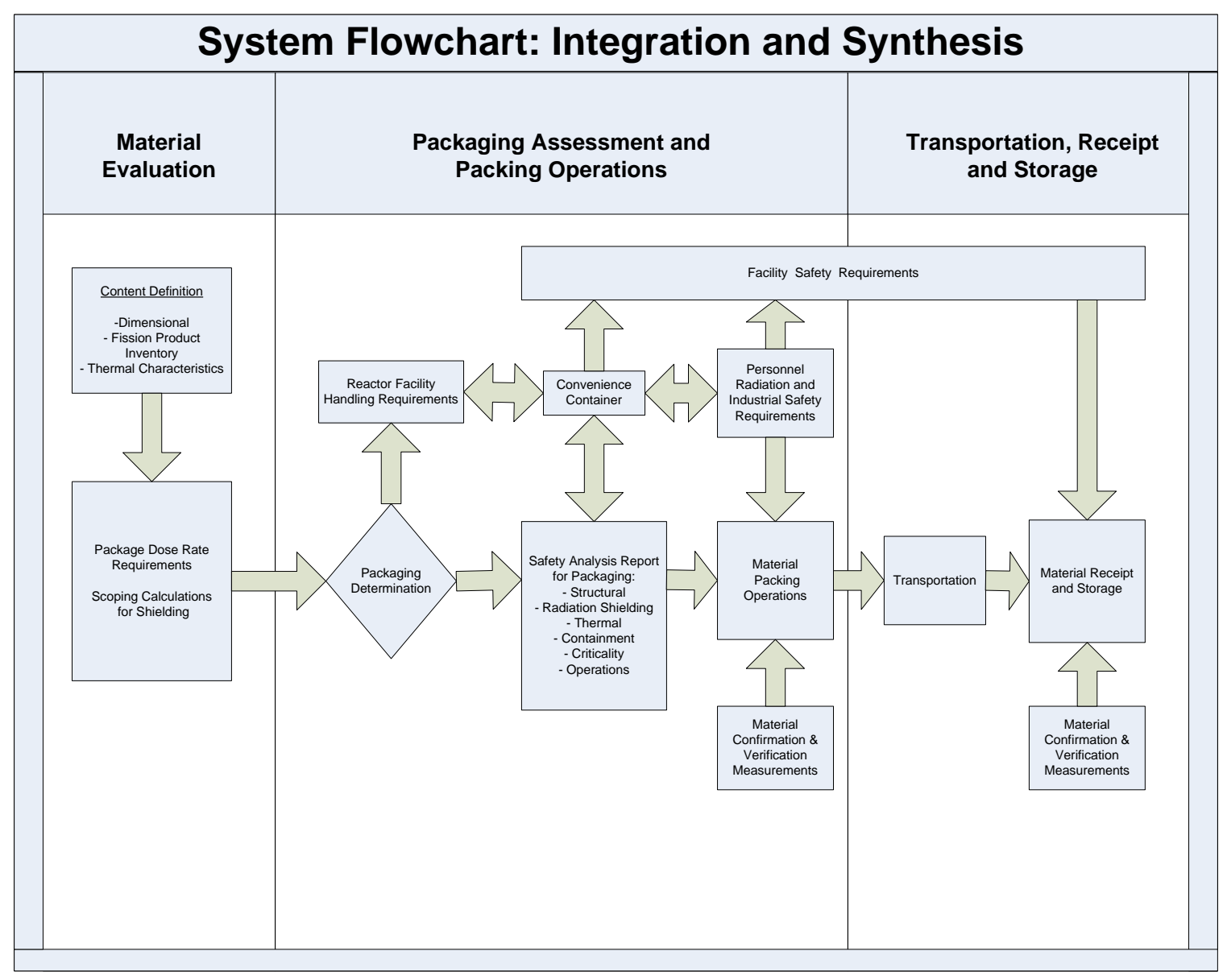

Figure 3. System Integration and Synthesis Flowchart

Successful problem resolution begins with establishing what needs to be accomplished based upon known parameters. Evaluate and select the best potential solution from among the alternatives based upon the known parameters. Perform the required analyses and document the results. Always be cognizant that decisions made may have significant impacts elsewhere. 